\title{
Dermocystidium sp. infection in cultured juvenile southern catfish Silurus meridionalis in China
}

\author{
Qizhong Zhang ${ }^{1,2, *}$, Zhijian Wang ${ }^{1}$ \\ ${ }^{1}$ School of Life Sciences, Southwest China Normal University, Chongqing 400715, PR China \\ ${ }^{2}$ Institute of hydrobiology, Jinan University, Guangzhou 510632, PR China
}

\begin{abstract}
A species of Dermocystidium was discovered on the skin and fins of reared southern catfish Silurus meridionalis Chen. The parasite only appeared and caused disease in juvenile catfish at a water temperature of 18 to $23^{\circ} \mathrm{C}$. Marked external macroscopical clinical signs of the disease were sluggish movement of the fish, and the appearance of white filiform dermal cysts varying in size (3-20 $\mathrm{mm}$ in length and $0.15-0.35 \mathrm{~mm}$ in width). Examination of both fixed and fresh mounts for light microscopy and of samples for transmission electron microscopy (TEM) showed spherical spores (3.2-15 $\mu \mathrm{m}$ in diameter) with a peripheral nucleus $(1.1-1.8 \times 0.5-1.6 \mu \mathrm{m}$ in diameter) and a prominent refractile body $(2.08-10.83 \mu \mathrm{m}$ in diameter) which occupied most of the volume of a mature spore. Three types of spore were identified, and are presumed to represent various developmental stages. Meanwhile, TEM showed the remnant nuclei in the residual plasmodium of a cyst, revealing its degenerative process. This paper represents the first observation and description of Dermocystidium sp. parasitizing catfishes.
\end{abstract}

KEY WORDS: Dermocystidium $\cdot$ Protozoa $\cdot$ Histology $\cdot$ Silurus meridionalis

Resale or republication not permitted without written consent of the publisher

\section{INTRODUCTION}

Dermocystidium is a genus comprised of unicellular parasites of fish and amphibians, with an uncertain taxonomic position. The minute spherical organisms have been assigned to the protozoa (Nash et al. 1989) or to lower fungi (Pauley 1967, Allen et al. 1968, Dykova \& Lom 1992) by different researchers. Ragan et al. (1996) allocated the taxon to a novel clade (provisional name 'DRIPs' clade) near the animal-fungal divergence. Herr et al. (1999) established a new clade called Mesomycetozoa for Rhinosporidium and DRIPs. Although controversy still exists about the taxonomic affinity of the species in the genus Dermocystidium, it is believed that the common feature of the genus is the existence of a spherical spore with a peripheral nucleus and a refractile body or large central vacuole as a stage of the developmental cycle (Höglund et al. 1997, Lotman et al. 2000). Dermocystidium spp. are occasionally found in amphibians (Pascolini et al. 2003), but most commonly occur in fishes, especially in juveniles, and they produce diseases which have been associated with fish mortalities (Pauley 1967, Allen et al. 1968, Hedrick et al. 1989, Nash et al. 1989, Olson \& Holt 1995). The genus Dermocystidium is known to include ca. 20 species (Lotman et al. 2000), but just 4 species have been reported in China, i.e. Dermocystidium koi Hoshina-Sahara, 1950, D. percae Reichenbach-Klinke, 1950, D. kwangtungensis Chen, 1956 and D. sinensis Xiao et Chen, 1993 (Xiao \& Chen 1993, Zhang et al. 1999). Although the genus is known from a wide variety of freshwater or marine fishes, to our knowledge no species has been reported from catfishes. This paper deals with a Dermocystidium species parasitizing juvenile southern catfish, Silurus meridionalis Chen.

\section{MATERIALS AND METHODS}

Fish. Juvenile catfish (8.2 to $15.3 \mathrm{~cm}$ in total length) for this study were sampled from net cages in Jialing River, Beibei, Chongqing, China. Fish were dissected and skin, including affected tissues, were sampled. 
Light microscopy. Spore morphology was examined in unstained fresh and/or formalin-fixed wet mounts in an Olympus BH-2 light microscope. The cysts were removed from the fish skin and immediately fixed and preserved in $5 \%$ buffered formalin. Affected skin, kidney, liver, spleen, gills and gonads were fixed with $5 \%$ buffered formalin or Bouin's fixative for at least $48 \mathrm{~h}$ before transferring them to $70 \%$ ethanol and embedding them in paraffin-wax blocks, sectioning at 6 to $8 \mu \mathrm{m}$ and staining with haematoxylin and eosin (H\&E), before finally examining them by light microscopy.

Electron microscopy. Cysts for transmission electron microscopy (TEM) were fixed in $2.5 \%$ glutaraldehyde in $0.1 \mathrm{M}$ phosphate buffer ( $\mathrm{pH} 7.2)$ at $4^{\circ} \mathrm{C}$ for $24 \mathrm{~h}$, and postfixed in $2 \% \mathrm{OsO}_{4}$ (in the same buffer) for $1 \mathrm{~h}$, dehydrated in graded series of ethanol, and embedded in Epon 812 resin. Ultra-thin sections were stained with uranyl acetate and lead citrate prior to examination with a Phillips transmission electron microscope.

\section{RESULTS}

\section{Clinical and gross pathology}

Infected juvenile southern catfish were emaciated, and swam sluggishly on the water's surface of net cages in the river. The infected catfish were covered with structures looking at first sight like white worms or winding white threads, which were subcutaneous (Figs. 1 to 3). Closer examination showed these structures to be cysts of the Dermocystidium sp., which were only observed in skin and fins of the catfish, and were not found in other organs. Cysts of different sizes ( 3 to $20 \mathrm{~mm}$ in length and 0.15 to $0.35 \mathrm{~mm}$ in width) were located in the dermis in an irregular way (Figs. 1 to 3). The anal fin was often found to bear cysts (Fig. 3). The infected sites of the fish skin displayed hyperaemia and oedema (Figs. 1 to 3). The epidermis at some parasitized locations was ruptured and had been shed (Fig. 2).

\section{Light microscopy}

Wet-mount preparations of fresh or fixed cyst contents of the Dermocystidium species revealed a massive number of spherical to oval spores which were ca. 3.2 to $15 \mu \mathrm{m}$ in diameter, with a refractile body (2.08 to
$10.83 \mu \mathrm{m}$ in diameter) (Fig. 4). The spores were not uniform, and occurred in different sizes even in the same cyst (Fig. 4). Microscopical examination of stained sections of the affected tissues revealed that the cyst wall in the dermis of the fish skin was surrounded by a hyperplastic connective tissue (Figs. 5 \& 7 ), in which inflammatory (predominantly mononuclear) cells were visible in some sections (Fig. 6). This suggested that the cysts provoke a slight inflammatory cell response in the tissue around the cysts. An epidermis layer overlying a cyst was occasionally observed
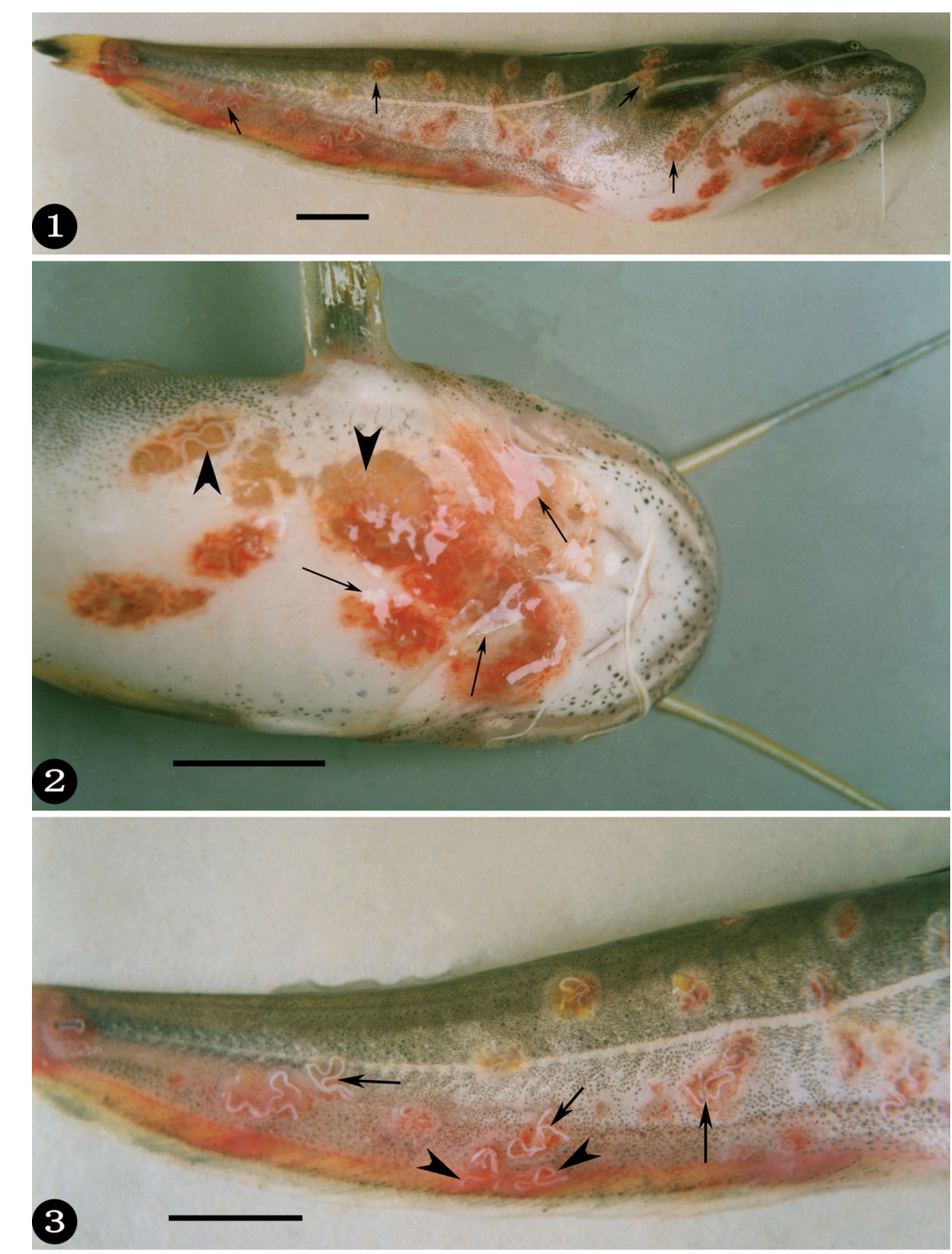

Figs. 1 to 3. Dermocystidium sp. infecting Silurus meridionalis. Infected juvenile southern catfish cultured in a net cage in Jialing River, Chongqing, China. Fig. 1. Individual juvenile catfish infected by Dermocystidium sp. Note ca. 42 pink or red parasitic sites; cysts of Dermocystidium sp. marked with arrows. Scale bar $=1 \mathrm{~cm}$. Fig. 2. Ventral view of the infected catfish. Note the parasitic sites displaying hyperaemia and oedema; ruptured epidermis marked with arrows, cysts of the parasite marked with arrowheads. Scale bar $=1 \mathrm{~cm}$. Fig. 3. Lateral view of the infected partial body; whitish cysts marked with $\overline{\text { arrows, }}$ cysts in the anal fin marked with arrowheads. Scale bar $=1 \mathrm{~cm}$ 


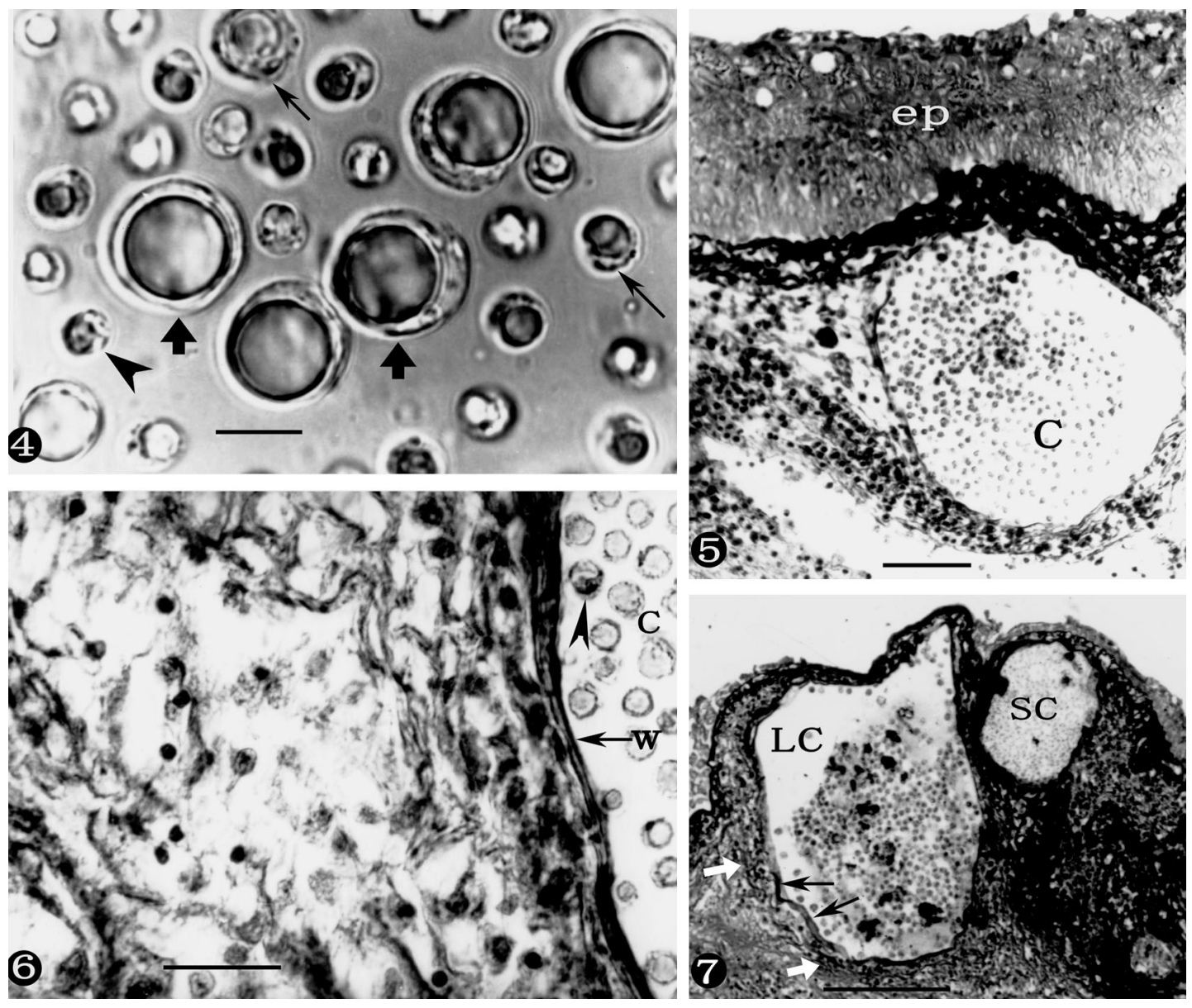

Figs. 4 to 7. Dermocystidium sp. infecting Silurus meridionalis. Photomicrographs of both a wet mount preparation of the Dermocystidium sp. and H\&E-stained sections of infected skin. Fig. 4. Wet mount of Dermocystidium sp. parasitizing the juvenile southern catfish; largest spores marked with bold arrows, medium-sized spores marked with thin arrows, smaller spore marked with an arrowhead. Scale bar $=10 \mu \mathrm{m}$. Fig. 5. A parasite cyst (C) within the catfish dermis containing numerous spores. Note the intact epidermis layer $(\mathrm{ep})$ overlaying the cyst. Scale bar $=50 \mu \mathrm{m}$. Fig. 6. Higher magnification of a cyst (c) and tissues around it. Note cyst wall (w), spores (arrowhead) and a slight infiltrate of mixed inflammatory cells to the left of the cyst. Scale bar $=20 \mu \mathrm{m}$. Fig. 7. Photomicrograph of 2-cyst cross section. Note the larger cyst (LC) enclosing larger spores than those in smaller cyst (SC), hyperplastic fibrous connective tissues (bold white arrows) around the cyst wall (thin arrows), and the epidermis layer overlaying the cysts has disappeared. Scale bar $=200 \mu \mathrm{m}$

(Fig. 5), but was often necrotic and had disappeared (Fig. 7). In summary, the catfish skin, especially the epidermis, was often destroyed by cysts.

\section{Electron microscopy}

Electron microscopy showed that the cyst wall of the Dermocystidium species was homogeneously thin and composed of just one layer (Fig. 8), which consisted of an aggregation of amorphous material; neither cellular components or membranes were found.

In spite of the various sizes, the spores possessed very similar structures, such as a thin spore membrane (Figs. 9 to 12), a large refractile body in most spores
(Figs. 10 to 12$)$, a spherical to oval nucleus $(1.1-1.8 \times$ $0.5-1.6 \mu \mathrm{m}$ in diameter) to one side towards the periphery of a spore (Figs. 9 to 12), mitochondria (Figs. 9, $11 \& 12$ ), and vacuoles (Figs. 9 to 12).

Several types of spore of different size and structure were observed. The first was small in diameter, and contained a prominent nucleus with a well-defined nucleolus, several vacuoles in various sizes, some mitochondria, and no refractile body (Fig. 9). The second was a medium-sized spore, with a refractile body of medium size, an obvious peripheral nucleus, some vacuoles and mitochondria in cytoplasm (Figs. 10 \& 11). The third was a large spore with a large refractile body occupying most of the space of a mature spore, a small nucleus without a nucleolus in the peripheral 

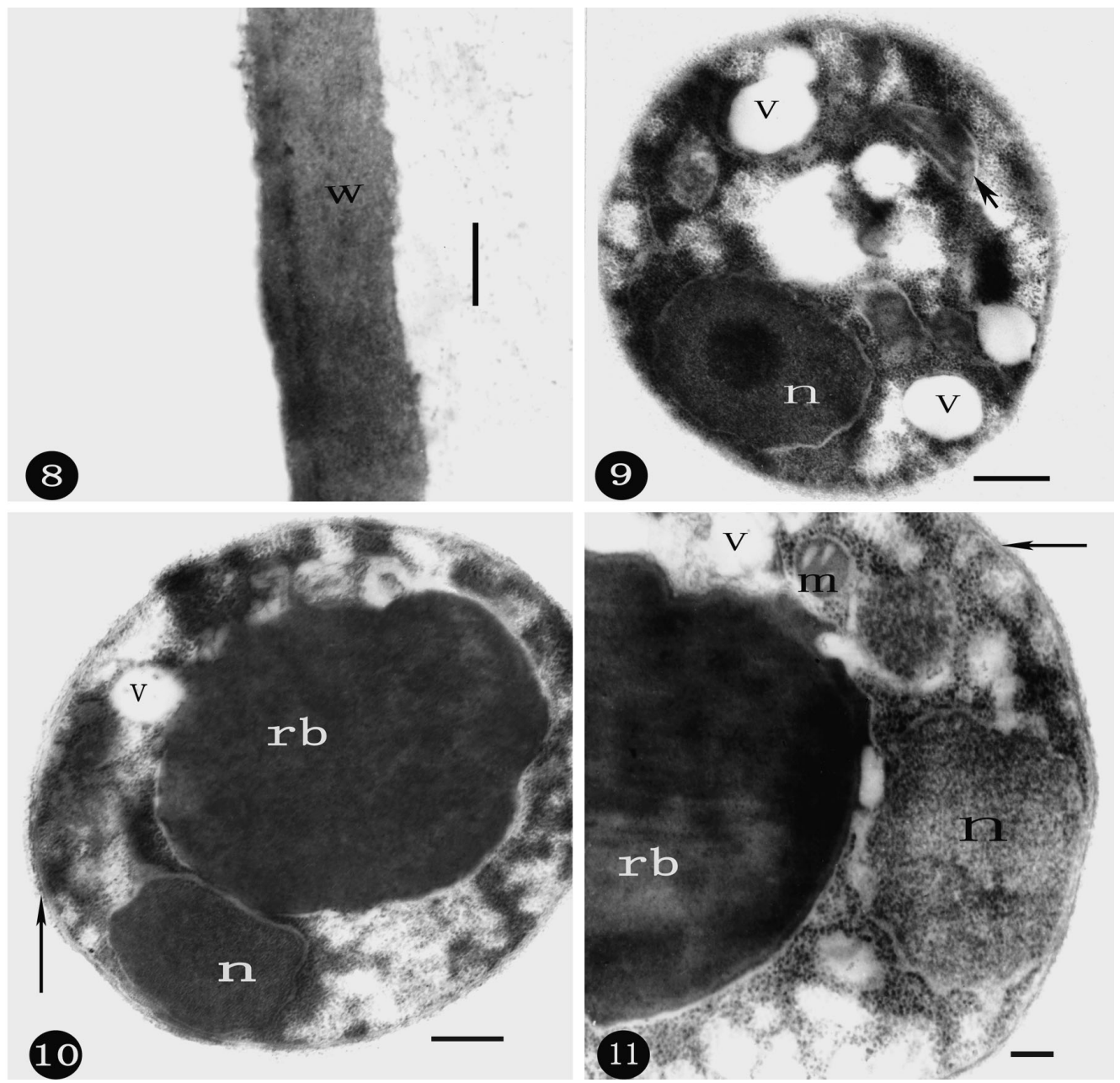

Figs. 8 to 11. Dermocystidium sp. infecting Silurus meridionalis. Transmission electron micrographs of cyst wall, small and medium-sized spores. Fig. 8. Cyst wall (w) consisting of an aggregation of amorphous material. Scale bar $=0.2 \mu \mathrm{m}$. Fig. 9. Small spore with a nucleus (n), mitochondrion (short arrow) and vacuoles (v), but without a refractile body. Scale bar $=0.5 \mu \mathrm{m}$. Fig. 10 . Medium-sized spore bearing a nucleus (n), a medium-sized refractile body (rb) and vacuole (v); thin arrow: thin spore membrane. Scale bar $=0.7 \mu \mathrm{m}$. Fig. 11. Partial medium-sized spore with a clear nucleus (n), mitochondrion (m), vacuoles (v) and a partial refractile body $(\mathrm{rb}) ;$ thin arrow: thin spore membrane. Scale bar $=0.2 \mu \mathrm{m}$

cytoplasm, and few other cellular organelles (Fig. 12). All 3 spore types possessed a thin, cellular membrane.

On the ultrastructural level, a deterioration of the residual plasmodium was observed in mature cysts (Fig. 13). The nuclei in the residual plasmodium did not have any role in the formation of spores, and became swollen and progressively vacuolated during the disintegration of the nucleoplasm (Fig. 14). The outer membrane of the remaining nuclei was separated from the inner one, and protruded outwards to form various vesicles (Figs. 14 [insert] \& 15). Numerous vesicles with ribosomes were observed in the remnant plasmodium (Fig. 16), and presumably came from the disintegrated nuclei. This sequence probably represents the degenerative process of residual plasmodium, especially the residual nuclei, in a cyst.

\section{DISCUSSION}

In the present study we describe spore morphology, histopathology and gross pathological signs of Dermocystidium species in the skin of reared juvenile catfish Silurus meridionalis Chen. This is, thus far, the first description of Dermocystidium species parasitizing catfish belonging to the order Siluriformis.

The most characteristic feature of the parasite described above is a spherical or oval spore with a refractile body and peripheral cytoplasm, which is the diagnostic feature of the genus Dermocystidium (Pauley 1967, Lotman et al. 2000). Additionally, the ultrastructures described above, i.e. the mitochondrion, vacuoles and a peripheral nucleus in the spore, are also characteristic of the genus Dermocystidium. It 


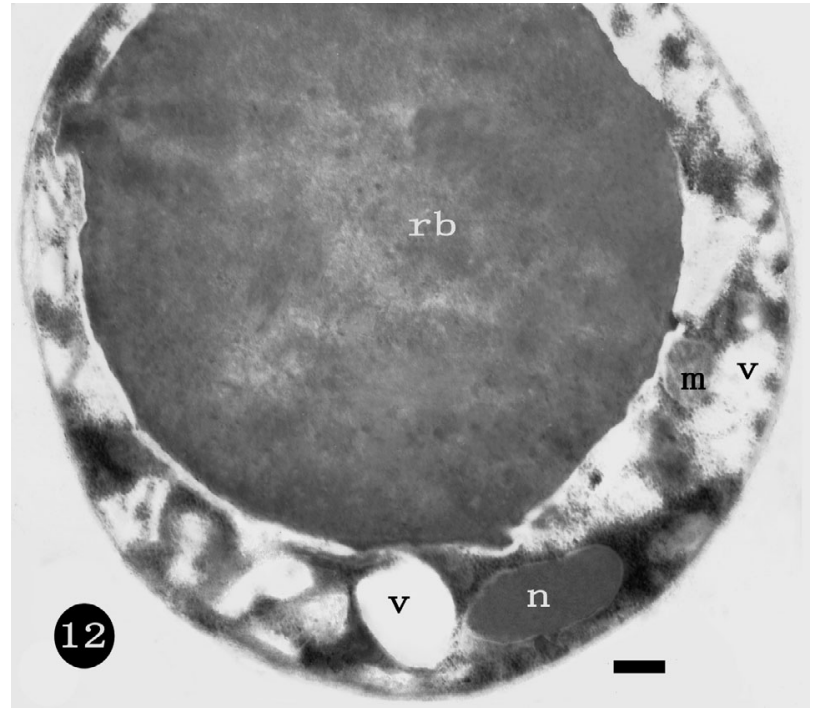

Fig. 12. Dermocystidium sp. infecting Silurus meridionalis. Transmission electron micrographs of a larger spore. Large refractile body (rb), a small nucleus (n), a mitochondrion (m) and a vacuole $(v)$ are shown. Scale bar $=1.2 \mu \mathrm{m}$ is therefore clear that the parasite in the catfish is definitely in the genus Dermocystidium. Moreover, this species resembles D. koi Hoshina and Sahara, 1950 and D. gasterostei Elkan, 1962 in the following respects (Hoshina \& Sahara 1950, Elkan 1962): (1) they were all parasitic in the skin or fins of fish, (2) they all possessed white worm-like or filiform cysts, (3) their hypnospores all had a peripheral nucleus and a large refractile body. However, the dimensions of spores and cysts differed, and the coenocytic cysts in the early developmental stage of the life cycle described for $D$. koi and D. gasterostei (Hoshina \& Sahara 1950, Elkan 1962, Dykova \& Lom 1992, Wildgoose 1995) were not apparent in the species we observed in the catfish. Therefore, its taxonomic name cannot be assigned confidently until further evidence about its life cycle is available, and it can only tentatively be named as Dermocystidium sp.

It has been reported that the early stage of the life cycle for some Dermocystidium spp. is a multinuclear plasmodium (Elkan 1962, Dykova \& Lom 1992, Lotman et al. 2000, Pekkarinen et al. 2003). Although the
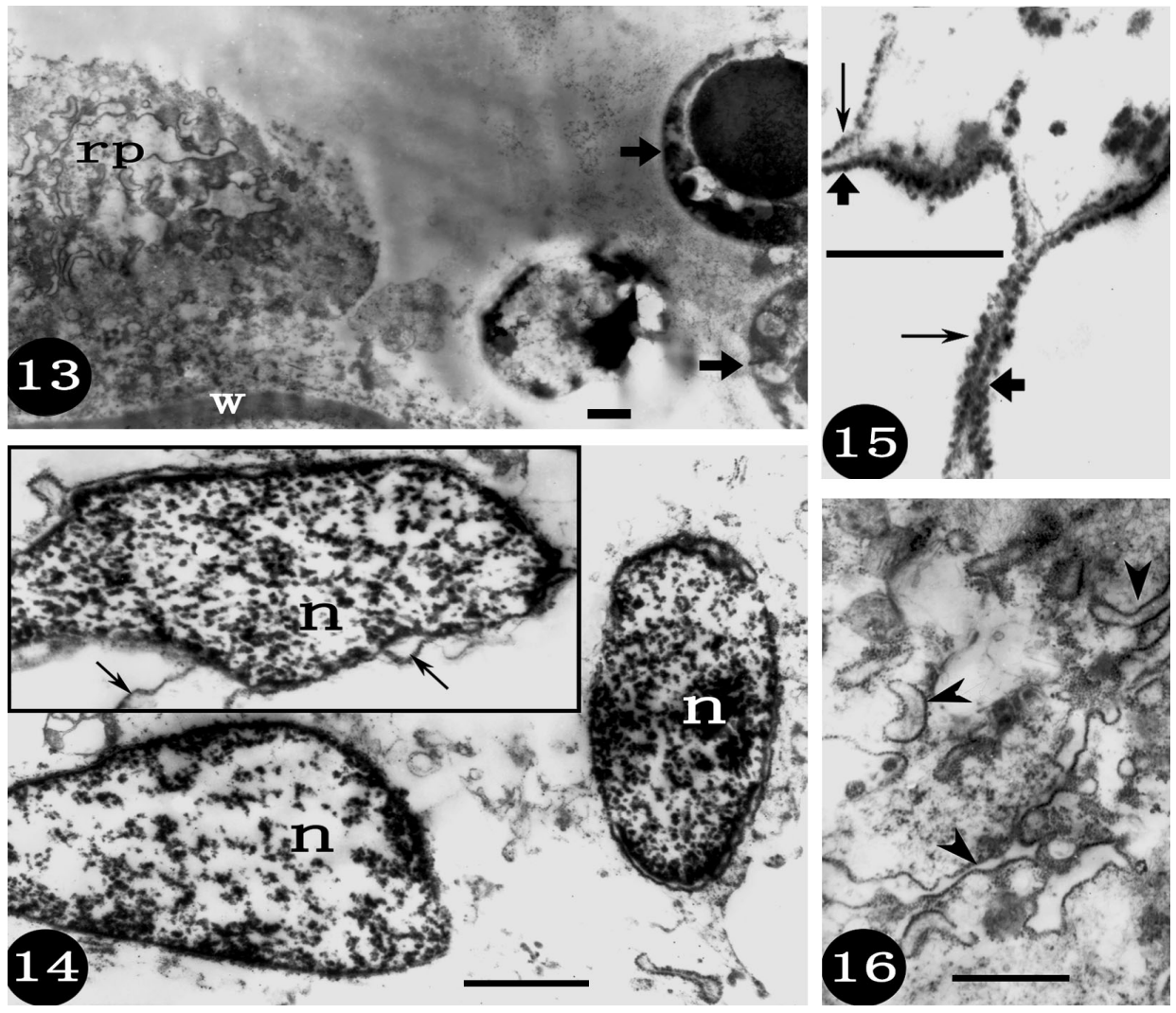

Figs. 13 to 16. Dermocystidium sp. infecting Silurus meridionalis. Transmission electron micrographs of the degenerative residual plasmodium in a mature cyst. Fig. 13. Residual plasmodium (rp) and spores marked with bold arrows in the cyst. w: cyst wall. Scale bar $=1 \mu \mathrm{m}$. Fig. 14. Residual nuclei (n) in the plasmodium. Insert: note the protruded outer membrane (arrows) of the remaining nucleus. Scale bar $=1 \mu \mathrm{m}$. Fig. 15. Higher magnification of a partial residual nucleus. Note the protruded outer membrane (bold arrows) with ribosomes (thin arrows). Scale bar $=0.5 \mu \mathrm{m}$. Fig. 16. Partial residual plasmodium. Note various vesicles (arrowheads) with ribosomes, probably resulting from the disintegration of residual nuclei. Scale bar $=1 \mu \mathrm{m}$ 
coenocytic plasmodium was not found in Dermocystidium sp., remnants of a multinuclear plasmodium were observed in mature cysts with spores, and the nuclei in the residual plasmodium were disintegrating. This suggests that the cyst containing spores probably came from an early coenocytic plasmodium stage.

The refractile body of the spore arose from a vacuole in Dermocystidium cyprini (Červinka et al. 1974), and acted as a possible nutrient source in D. gasterostei Elkan, 1962, when the spore entered a new host (Elkan 1962). This suggests that the refractile body appeared after the vacuole in the spore. Based on the absence or presence and various sizes of refractile bodies, a hypothesis is proposed to deduce the possible developmental process of the young spores of Dermocystidium sp. observed in the catfish, viz.: the first type of spore, with vacuoles and no refractile body, develops into the second type with a small refractile body, and goes into the third type, with a large refractile body.

Dermocystidium sp. was only found from cultured catfish in net cages of Jialing River, and not from catfish in ponds. It only appeared in juvenile catfish from mid-May to June when the water temperature was 18 to $23^{\circ} \mathrm{C}$, which was similar to the temperature for the appearance of $D$. koi in carp (Wildgoose 1995). However, at the same range of water temperature from October to mid November in Jialing River, the parasite was not found in the catfish, and they went on to grow into adults (Zhang \& Wang unpubl. obs.). This suggests transmission of the parasite from wild catfish or other fishes to reared juvenile catfish in the net cages of the river, and that juvenile catfish were more susceptible to the parasite than adults.

In addition to the infection of the parasite, bacterial plates yielded growth of some bacteria, which were not identified for its taxonomic position, when they were inoculated from the focal lesions caused by the parasite in the skin of the catfish (Zhang \& Wang unpubl. obs.). Therefore, both Dermocystidium and bacteria concurrently infected the juvenile catfish, and were responsible for about 3 to $5 \%$ mortality of the juveniles. Similar observations were made regarding concurrent infections of Dermocystidium spp. and bacteria by other authors (Pauley 1967, Höglund et al. 1997), and Pauley (1967) thought that the bacterium was a secondary invader. Höglund et al. (1997) did not determine whether the bacterium was the primary or secondary infectious pathogen. However, the bacteria could be presumed to be secondary invaders in this study, because bacterial infections only occurred in the lesions caused by Dermocystidium sp.

Acknowledgements. The authors are indebted to $\operatorname{Dr} \mathrm{M}$. Pekkarinen, Department of Biosciences, Division of Animal Physiology, University of Helsinki, Finland, and Dr J. Höglund,
Department of Parasitology, National Veterinary Institute and Swedish University of Agricultural Sciences, for offering their published papers, and are also grateful to Dr G. T. Wang for providing some literature. This work was supported by both the Key Scientific and Technological Project of Chongqing and the Natural Science Foundation of Chongqing.

\section{LITERATURE CITED}

Allen RL, Meekin TK, Pauley GB, Fujihara MP (1968) Mortality among Chinook salmon associated with the fungus Dermocystidium. J Fish Res Board Can 25:2467-2475

Červinka S, Vítovec J, Lom J, Hoška J, Kubů F (1974) Dermocystidiosis - a gill disease of the carp due to Dermocystidium cyprini n. sp. J Fish Biol 6:689-699

Dykova I, Lom J (1992) New evidence of fungal nature of Dermocystidium koi Hoshina and Sahara, 1950. J Appl Ichthyol 8:180-185

Elkan E (1962) Dermocystidium gasterostei n. sp., a parasite of Gasterosteus aculeatus L. and Gasterosteus pungitius L. Nature 196:958-960

Hedrick RP, Friedman CS, Modin J (1989) Systemic infection in Atlantic salman Salmo salar with a Dermocystidium-like species. Dis Aquat Org 7:171-177

Herr RA, Ajello L, Taylor JW, Arseculeratne SN, Mendoza L (1999) Phylogenetic analysis of Rhinosporidium seeberi's 18s small-subunit ribosomal DNA groups this pathogen among members of the protoctistan mesomycetozoa clade. J Clin Microbiol 37:2750-2754

Höglund J, Alfjorden A, Nikkilä T (1997) Infection of juvenile salmon Salmo salar with a Dermocystidium-like organism in Sweden. Dis Aquat Org 30:171-176

Hoshina T, Sahara Y (1950) A new species of the genus Dermocystidium, D. koi sp. nov., parasitic in Cyprinus carpio L. Bull Jpn Soc Sci Fish 15:825-829 (in Japanese with English abstract)

Lotman K, Pekkarinen M, Kasesalu J (2000) Morphological observations on the life cycle of Dermocystidium cyprini Červinka and Lom, 1974, parasitic in carps (Cyprinus carpio). Acta Protozool 39:125-134

Nash G, Southgate P, Richards RH, Sochon E (1989) A systemic protozoal disease of cultured salmonids. J Fish Dis 12:157-173

Olson RE, Holt RA (1995) The gill pathogen Dermocystidium salmonis in Oregon salmonids. J Aquat Anim Health 7:111-117

Pascolini R, Daszak P, Cunningham AA, Tei S, Vagnetti D, Bucci S, Fagotti A, Di Rosa I (2003) Parasitism by Dermocystidium ranae in a population of Rana esculenta complex in central Italy and description of Amphibiocystidium n. gen. Dis Aquat Org 56:65-74

Pauley GB (1967) Prespawning adult salmon mortality associated with a fungus of the genus Dermocystidium. J Fish Res Board Can 24:843-848

Pekkarinen M, Lom J, Murphy CA, Ragan MA, Dyková I (2003) Phylogenetic position and ultrastructure of two Dermocystidium species (Ichthyosporea) from the common perch (Perca fluviatilis). Acta Protozool 42:287-307

Ragan MA, Goggin CL, Cawthorn RJ, Cerenius L and 5 others (1996) A novel clade of protistan parasites near the animal-fungal divergence. Proc Natl Acad Sci USA 93:11907-11912

Wildgoose WH (1995) Dermocystidium koi found in skin lesions in koi carp (Cyprinus carpio). Vet Rec 137:317-318

Xiao C, Chen C (1993) A new species-Dermocystidium sinensis sp. nov. from freshwater fishes of China. Trans Res Fish Dis 1:95-97 (in Chinese with English abstract)

Zhang J, Qiu Z, Ding X (1999) Parasites and parasitic diseases of fishes. Science Press, Beijing, China (in Chinese) 